\title{
Research trends in studies of medical students' characteristics: a scoping review
}

\author{
Sung Soo Jung ${ }^{1}$, Kwi Hwa Park ${ }^{2}$, HyeRin Roh ${ }^{3}$, So Jung Yune, ${ }^{4}$ Geon Ho Lee ${ }^{5}$ and Kyunghee Chun ${ }^{6}$ \\ ${ }^{1}$ Department of Internal Medicine, Chungnam National University College of Medicine, Daejeon, ${ }^{2}$ Department of \\ Medical Education, Gachon University College of Medicine, Incheon, ${ }^{3}$ Department of Medical Education and the \\ Institute of Medical Humanities, Inje University College of Medicine, ${ }^{4}$ Department of Medical Education, Pusan \\ National University College of Medicine, Busan, ${ }^{5}$ Department of Family Medicine, Catholic University of Daegu \\ School of Medicine, Daegu, and ${ }^{6} \mathrm{Head}$ Office for Educational Innovation, Tongmyong University, Busan, Korea
}

The purpose of this study is to investigate domestic and international research trends in studies of medical students' characteristics by using the scoping review methods. This study adopted the scoping review to assess papers on the characteristics of medical students. The procedure of research was carried out according to the five steps of the scoping review. The full texts of 100 papers are obtained and are read closely, after which suitable 88 papers are extracted by us for this research. The review is mapped by the year of the study, source, location, author, research design, research subject, objective, and key results. The frequency is analyzed by using Microsoft Excel and SPSS. We found 70 papers (79.5\%) on a single medical school, 15 (17.0\%) on multiple medical schools, and three $(3.4 \%)$ on mixed schools, including medical and nonmedical schools. Sixty-nine (79.5\%) were cross-sectional studies and $18(20.5 \%)$ were longitudinal studies. Eighty-two papers (93.2\%) adopted questionnaire surveys. We summarized research trends of studies on medical students in Korea and overseas by topic, and mapped them into physical health, mental health, psychological characteristics, cognitive characteristics, social characteristics, and career. This study provides insights into the future directions of research for the characteristics of medical students.

Key Words: Review, Medical students, Medical schools

\section{Introduction}

The three elements of education are teachers, learners, and contents. Since the subject of educational activities is for the learners, it is important to understand the characteristics of the learners before the educational activities are started. The characteristics of learners refer to behavior characteristics of them. This is largely divided into cognitive and affective characteristics. Information on learner characteristics is important because it directly or indirectly influences the development of curriculum, deciding on teaching methods, and guiding students [1]. Meanwhile, students have different personalities or motivations depending on their generation to which they belong [2,3]; this affects teaching methods such as the use of media technology like video clips, or demand for the teacher's specific guidance and
Received: June 22, 2017 • Revised: July 26, 2017 • Accepted: July 31, 2017 Corresponding Author: Kwi Hwa Park (https://orcid.org/0000-0002-0008-2400) Department of Medical Education, Gachon University College of Medicine, 38 Dokjeom-ro 3beon-gil, Namdong-gu, Incheon 21565, Korea

Tel: +82.70.7120.7902 Fax: +82.32.464.5004 email: ghpark@gachon.ac.kr
Korean J Med Educ 2017 Sep; 29(3): 137-152.

https://doi.org/10.3946/kjme.2017.60

eISSN: 2005-7288

(C) The Korean Society of Medical Education. All rights reserved. This is an open-access article distributed under the terms of the Creative Commons Attribution Non-Commercial License (http:// creativecommons.org/licenses/by-nc/3.0/), which permits unrestricted non-commercial use, distribution, and reproduction in any medium, provided the original work is properly cited. 
feedback $[4,5]$. Thus, research on the characteristics of learners is important in terms of providing the basic data required for the teachers to understand the learners.

Learner characteristics are an important research topic in all disciplines, and this is no exception in the field of medical education. In Korea, the departments of medical education have been established and the importance of medical education has increased [6,7]. Research on medical education, thus, has also become active. According to one study, in 386 papers about medical education studies from 1989 to 2010, most of them-about 106 (27.5\%) - were related to medical curriculum, while about 27 (7\%) were about the characteristics of medical students [8]. According to another study, there has been a dramatic increase in research on the characteristics of medical students for the last 10 years [9]. However, only one conducted a literature review presenting new trends by specifying the characteristics of medical students from cognitive, emotional, and social aspects [10]. This has limitations in that only the domestic papers are analyzed. Although there are also many other studies conducted in Korea on characteristics of medical students, but it is difficult to find articles that include comprehensive analysis about domestic and foreign study trends and that present study direction by comparatively analyzing domestic study trends with foreign ones.

To examine trends of research on medical students in Korea and overseas, this study adopted a literature review method called the scoping review. While the systematic review looks at empirical evidence for more specific and detailed research questions, the scoping review offers a clear and intelligible mapping of research areas, and is used for a literature review that has never been carried out extensively before. This is why it is often used as a preliminary step of systematic reviews [11]. To the best of our knowledge, no research has analyzed studies on characteristic of medical students of
Korean ones and those of oversea countries. Accordingly, this study will investigate domestic and international research trends, mapping them by research topic using the scoping review methods, execute an in-depth analysis of the findings of subtopics in this area and suggest directions for the future research.

\section{Methods}

\section{Study design}

This study adopted the scoping review method for reviewing papers on the characteristics of medical students. As previously mentioned, the scoping review is mostly used for the research of which review has never been conducted extensively and is used in order to provide basic data for beginning a new field of the study by mapping research areas and exploring the primary data and evidence of the research [11,12]. This study adopted such a method considering that it is suitable for the present situation in which no review exists on literature pertaining to the traits of medical students.

\section{Procedure}

The procedure of research was carried out according to the five steps of the scoping review [12,13]: (1) identifying the research question; (2) identifying relevant studies; (3) study selection; (4) charting the data; (5) collating, summarizing, and reporting the results. The study methods are described up to Step 4, while Step 5 includes the Results.

\section{1) Research question}

A considerable literature can be found if the research questions are selected in a broad range via the scoping review [11]. Since 2005, there has been a significant increase in the studies on characteristic of medical 
students in Korea [9]. Accordingly, it is necessary to examine the directions of such studies in Korea comparing those of other countries, and also to determine the results of such investigations. Therefore, the research question in this study is "What is the direction of studies on characteristic of medical students in Korea and overseas, and what the differences are?"

\section{2) Search strategy of relevant studies}

The relevant studies used are those related to the characteristics of medical students published in Korea and overseas from January 2010 to February 2016. The reason of choosing the year 2010 as the starting point is to actively reflect the recent status to research studies that include the latest medical students born since the 1990s.

The databases used include PubMed, Scopus, EBSCO, DBpia, RISS, and KISS. The search keywords that are set up are "(medical AND student) or (medical AND school)" in titles and abstracts. We also searched for limited keywords that can be considered attributes of medical students along with AND. We perused data March 3 to 5, 2016. We excluded papers, contributions, or text books in languages other than Korean or English.

a. Inclusion criteria: vision, goal, idealism, applicants, admission, selection, motive (or motivation), personality, characteristics, learning, learning style, achievement, performance, smoking, drinking, sleeping, mental health, stress, burnout, (life) quality, psychological support, professionalism, attitude, perceptions, environment, career selection, specialty choice, licensing (license)

b. Exclusion criteria: curriculum design, educational methods, educational evaluation, medical education environment, admission variable

\section{3) Study selection}

The process of collecting and selecting the data is as follows. When "(medical AND student) or (medical AND school)" is searched in the databases, 3,838 papers are

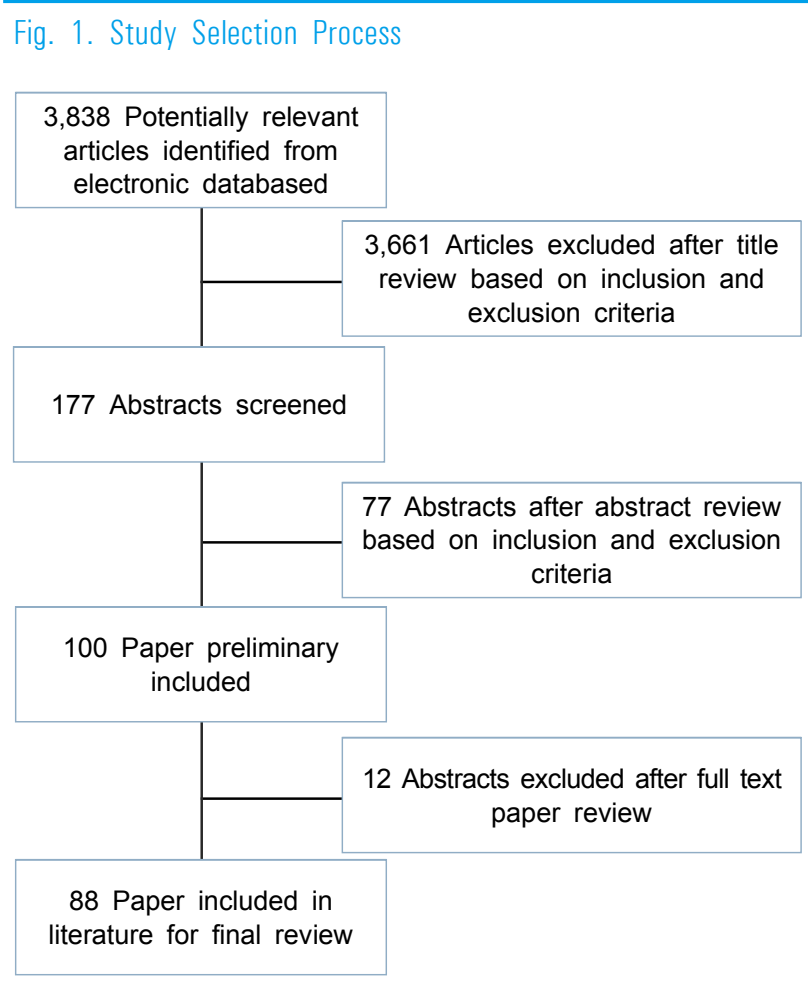

found. One hundred seventy-seven papers are extracted after eliminating redundant papers by looking at the titles applying the inclusion and exclusion criteria. After reading the abstracts, 100 papers are selected and 77 that were unrelated to the research are excluded, which are about an exclusion criterion of this study. The full texts of the 100 papers are obtained and read closely, after 88 suitable for research are extracted. The data collection, selection, and extraction processes are as follows (Fig. 1).

\section{4) Data recording}

A scoping review can be mapped by author, year of publication, location, number of research subjects, research objective, research method, result measurement, results, and conclusion [12]. We mapped our review by the year of publication, location of research, research design, research subject, objective, research method, and key results. The topic was categorized by discussion of six researchers. The researchers reviewed key results and made a list of subtopics based on them. And similar subtopic lists were categorized into six research areas. 


\section{5) Data summary and synthesis}

After inputting data into Microsoft Excel based on the mapping criteria, the frequency is analyzed and the percentage using the IBM SPSS ver. 23.0 (IBM Corp., Armonk, USA) is obtained.

\section{Results}

\section{Analysis of the general traits of studies on medical students in Korea and overseas}

Using the year of study, we found 12 papers (13.6\%) from 2010, 8 (9.1\%) from 2011, 12 (13.6\%) from 2012, 18 (20.5\%) from 2013, 12 (13.6\%) from 2014, 20 (22.7\%) from 2015, and 6 (6.8\%) from 2016. Using the study situation, we found 70 papers $(79.5 \%)$ on a single medical school, 15 (17.0\%) on multiple medical schools, and 3 (3.4\%) on mixed schools, including medical and nonmedical schools. Sixty-nine (79.5\%) were cross-sectional studies and 18 (20.5\%) were longitudinal studies. As for methods, 82 papers (93.2\%) adopted questionnaire surveys (Table 1). Moreover, by location, excluding Korea, 22 studies were conducted in Asia, 14 in European countries including the United Kingdom, 9 in North America, 2 in Austria, and 4 in South America.

Table 1. General Characteristics of Research

\begin{tabular}{|c|c|c|c|c|c|}
\hline \multirow{2}{*}{ Characteristic } & \multicolumn{2}{|r|}{ Domestic } & \multicolumn{2}{|r|}{ International } & \multirow{2}{*}{ Total } \\
\hline & №. $(\%)$ & Reference & №. $(\%)$ & Reference & \\
\hline \multicolumn{6}{|l|}{ Year of publication } \\
\hline 2016 & $2(5.4)$ & {$[15,19]$} & $4(7.8)$ & {$[14,16-18]$} & $6(6.8)$ \\
\hline 2015 & $7(18.9)$ & {$[25,34-39]$} & $13(25.5)$ & {$[20-24,26-33]$} & $20(22.7)$ \\
\hline 2014 & $7(18.9)$ & {$[45-51]$} & $5(9.8)$ & {$[72,78-81]$} & $12(13.6)$ \\
\hline 2013 & $7(18.9)$ & {$[58,64-69]$} & $11(21.6)$ & {$[52-57,59-63]$} & $18(20.5)$ \\
\hline 2012 & $5(13.5)$ & {$[72,78-81]$} & $7(13.7)$ & {$[70,71,73-77]$} & $12(13.6)$ \\
\hline 2011 & $4(10.8)$ & {$[85,87-89]$} & $4(7.8)$ & {$[82-84,86]$} & $8(9.1)$ \\
\hline 2010 & $5(13.5)$ & [97-101] & 7 (13.7) & [90-96] & $12(13.6)$ \\
\hline \multicolumn{6}{|l|}{ Research situation } \\
\hline Single medical school & $30(81.1)$ & $\begin{array}{l}{[15,19,25,34,36,38,39,45-47,} \\
49-51,58,64-69,78-81,85,87, \\
97-100]\end{array}$ & $40(78.4)$ & $\begin{array}{l}{[15,19,25,34,36,38,39,45-47,49} \\
-51,58,64-69,78-81,85,87,97- \\
100]\end{array}$ & $70(79.5)$ \\
\hline Multiple medical school & $5(13.5)$ & {$[37,48,72,88,89]$} & $10(19.6)$ & {$[16,18,23,31,41,43,71,74,90,96]$} & $15(17.0)$ \\
\hline Mixed school & $2(5.4)$ & {$[35,101]$} & $1(2.0)$ & {$[94]$} & $3(3.4)$ \\
\hline \multicolumn{6}{|l|}{ Research design } \\
\hline Cross-sectional study & $35(94.6)$ & $\begin{array}{l}{[19,25,34-39,45-51,64-69,72,} \\
78-81,85,87-89,97-101]\end{array}$ & $35(68.6)$ & $\begin{array}{l}{[14,17-21,23,26-28,30-32,41-44,} \\
52-55,57,59,62,74-77,82,84,91- \\
96]\end{array}$ & $70(79.5)$ \\
\hline Longitudinal study & $2(5.4)$ & {$[15,58]$} & $16(31.4)$ & $\begin{array}{l}{[16,22,24,29,33,40,56,60,61,63,} \\
70,71,73,83,86,90]\end{array}$ & $18(20.5)$ \\
\hline \multicolumn{6}{|l|}{ Research method } \\
\hline Questionnaire & $33(89.2)$ & $\begin{array}{l}{[15,19,25,35,37-39,45-51,58,65} \\
-69,72,78,80,81,85,87-89,97- \\
101]\end{array}$ & $49(96.1)$ & $\begin{array}{l}{[14,16-18,20-24,26,28-33,40-44,} \\
52-57,59-63,70,71,73-77,82-84 \\
86,90-92,94-96]\end{array}$ & 82 (93.2) \\
\hline Interview & $2(5.4)$ & {$[34,36]$} & $2(3.9)$ & {$[27,93]$} & $4(4.5)$ \\
\hline Mixed & $1(2.7)$ & [64] & 0 & - & $1(1.1)$ \\
\hline Observation & $1(2.7)$ & [79] & 0 & - & $1(1.1)$ \\
\hline
\end{tabular}




\section{Analysis of study topics on medical student characteristics}

Research trends of studies on medical student characteristics in Korea and overseas by topic are summarized, and mapped into physical health, mental health, psychological characteristics, cognitive characteristics, social characteristics, and career (Table 2). Most studies were on medical students' mental health, 30 from Korea and 34 from overseas. Among subtopics in mental health, investigations on stress comprised most papers, 10 from Korea and 13 from overseas. Regarding subtopics of mental health, in Korea, there are no studies about anxiety, drugs, or suicide.

There were 18 studies on psychological features from Korea and five other countries from overseas, as well as 14 on cognitive attributes from Korea and nine countries from overseas, indicating that both areas were studied more in Korea. There were four studies in Korea on self-efficacy (a subtopic of psychological character-

Table 2. Categorization of Research Themes

\begin{tabular}{|c|c|c|c|}
\hline Theme & Domestic & International & Total \\
\hline Physical health & 6 & 9 & 15 \\
\hline Health perception & - & 2 & 2 \\
\hline Sleep & 4 & 3 & 7 \\
\hline Drinking & - & 2 & 2 \\
\hline Fatigue & 1 & - & 1 \\
\hline Smoking & 1 & 2 & 3 \\
\hline Mental health & 30 & 34 & 64 \\
\hline Quality of life & 4 & 1 & 5 \\
\hline Mental & 1 & 2 & 3 \\
\hline Burn out & 5 & 2 & 7 \\
\hline Anxiety & - & 3 & 3 \\
\hline Stress & 10 & 13 & 23 \\
\hline Substance & - & 1 & 1 \\
\hline Depression & 6 & 9 & 15 \\
\hline Suicide & - & 3 & 3 \\
\hline Adjustment & 3 & - & 3 \\
\hline Happiness & 1 & - & 1 \\
\hline Affective & 18 & 5 & 23 \\
\hline Empathy & 2 & 1 & 3 \\
\hline Attribution & 1 & - & 1 \\
\hline Self-efficacy & 4 & - & 4 \\
\hline Ethical belief & 1 & - & 1 \\
\hline Motivation & - & 1 & 1 \\
\hline Personality & 4 & 1 & 5 \\
\hline Perfectionism & 1 & - & 1 \\
\hline Self-esteem & 3 & 1 & 4 \\
\hline Ego resilience & 1 & - & 1 \\
\hline Emotion intelligence & 1 & 1 & 2 \\
\hline
\end{tabular}

(Continued to the next page) 
Table 2. (Continued)

\begin{tabular}{lccc}
\hline \multicolumn{1}{c}{ Theme } & Domestic & Tnternational & 23 \\
\hline Cognitive/learning & 14 & 9 & 2 \\
Performance goal & 1 & 1 & 4 \\
Drop out & 3 & 1 & 5 \\
Learning motivation & 1 & 4 & 4 \\
Learning style & 1 & 3 & 5 \\
Learning strategy & 5 & - & 3 \\
Learning attitude & 3 & - & 15 \\
Social & 7 & 8 & 5 \\
Interrelationship & 4 & 1 & 3 \\
Coping & 1 & 2 & 1 \\
Leadership & - & 1 & 4 \\
Social support & 2 & 2 & 2 \\
Professional behavior & - & 2 & 18 \\
Career & 4 & 14 & 9 \\
Family variable & - & 1 & 3 \\
Preference & 1 & 8 & 3 \\
Personality/trait & 1 & 2 & 1 \\
Entering motivation & - & 3 & 158 \\
Career value & 1 & - & - \\
Major satisfaction & 1 & 79 & 1 \\
Total & & & \\
\hline
\end{tabular}

istics), four on personality, and three on self-esteem. As for the subtopics of cognitive traits, five studies were on learning strategies, three on learning attitudes, and three on flunking. Three studies in Korea and 14 overseas were on careers, showing that more oversea studies were about this topic.

\section{Analysis of the results by topics regarding studies on medical student characteristics}

Our analysis of the results and the study traits are presented based on subtopics that were frequently appeared in both Korea and overseas and are sorted into six research areas.

\section{1) Analysis of the research results related to physical health}

Studies about physical health covered topics such as health awareness, sleep, drinking, fatigue, and smoking. The quality of sleep was not favorable for medical students in Korea or overseas [14,65]. The average hours of sleep on weekdays for medical students in both Korea and overseas was less than 6 hours, indicating that medical students are suffering lack of sleep. There were also cases in which the hours of sleep were 5 hours or less (27.8\%) [32]. As for sleeping patterns, most students (95.3\%) were either afternoon types or evening types and the latter kind was more common among male students [66]. A third of the students complained of daytime sleepiness [32]. The interesting thing about Korean medical students is that they sleep less but tend to have a higher quality of sleep as they move on to their later years in school $[20,65]$. There were no gender differences regarding hours of sleep, but that female students sleep longer on weekdays was shown, while male students sleep longer on weekends [65]. There is an extremely low rate of seeking counseling for lack of sleep, despite the many issues related to it. Only $13.5 \%$ of students 
received counseling for sleeping pattern problems [20]. About two-thirds of medical students complained of fatigue, which is more frequent than general adults. There was no relevance between medical students and fatigue in terms of ages or genders [46]. As for drinking alcohol in overseas studies, at least $80 \%$ of students drank for 1 month, one-third of whom were involved in heavy drinking [54]. Fourteen percent of the students took part in hazardous drinking during their school years, and among those who showed severe drinking behaviors (since they were students), about one-fourth were also constantly involved in hazardous drinking, even after becoming doctors [16]. However, no studies in Korea have covered issues related to drinking alcohol. As for smoking, the ratio of smokers among graduate entry medical students was at least twice (25.9\%) higher than those in the United States at 9\% [65].

\section{2) Analysis of the results related to mental health}

Mental health was the most commonly covered issue in Korea and overseas, including topics such as stress, burnout, depression, anxiety, suicide, and quality of life. The key stress factors of medical students included academic achievement and excessive exams [35,44,60], excessive extracurricular activities, competition with fellow students and family matters [44], financial issues [60], changes in social life [35], experiencing a death [35], and marriage [60]. Some studies claim that female students suffer more from stress [88], while others maintain that male students suffer more [60]. Female students feel more stress in teaching-learning situations, interpersonal relations, and group activities [92], whereas male students show greater stress due to social expectations [60]. Subjective stress was higher for pre-medical school students and medical students than graduate-entry medical students [85]. By year, the studies showed inconsistent results, with some asserting that stress is greatest in the third year [29,52,80,92], and others claiming that stress decreases as the year gets higher $[60,68]$.

Academic stress is the main source of stress for medical students [44], about $56 \%$ of students constantly suffered from this [32]. This number decrease as the year gets higher [68,80]. Some studies show that academic stress is higher for first-year students [80], while others show that it is greater among higher-year students. Academic stress makes no difference according to gender and educational system [37].

As for burnout, at least one-fourth of graduate entry medical students in Korea experience a high level of it, which is lower than the United States but higher than the United Kingdom and Spain [25]. Female students show more emotional exhaustion [25,39], but there are no gender differences in some results [38,50]. Burnout is also linked with depression, poor grades, concerns flunking, academic self-efficacy, and the burden of one's studies $[38,39,50]$.

Around $10 \%$ of medical students express symptoms of depression [73]. Twenty-eight percent score at least 16 points for risk of depression [29,31]. Male students show much more serious symptoms [30,63], with $2.2 \%$ exhibiting a severe level of depression [80]. Students that are flunked or took time off from school suffer greatly from psychological anxiety and depression [81]. Depression tends to decline as the year gets higher $[63,73,80]$.

No study on suicide conducted in Korea is found. Medical students demonstrate a low level of suicide attempts in overseas studies, but suicidal ideation is high at 23\% [30]. The ideation of suicide attempts is higher among females [43]. Students who tried to commit suicide the previous year tend to repeat and the ratio increase among students in the lower years [30].

\section{3) Analysis of the results related to psychological (affective) characteristics}

Studies on psychological characteristics cover topics 
such as empathy, self-efficacy, personality, perfectionism, self-esteem, and motivation. There is a greater difference in psychological qualities based on educational system or gender rather than year.

Lower-year students show higher scores for empathy, while female students expressed higher empathic abilities in Korea and overseas [70]. Medical students have lower academic self-efficacy than non-medical students [19,101], academic self-efficacy is also linked with academic achievement [75]. Studies on personality types reveal that medical students mostly demonstrated remarkable results in terms of being introverted sensing thinking judging and extroverted sensing thinking judging according to the Myers-Briggs Type Indicator [69], and are focused on "body" with the highest rate of Type 9 in the Enneagram. In terms of mental state, about half (51.7\%) of the students are stressed out [89]. Medical students have low positive expectations for themselves compared to non-medical students [101]. Compared with graduate entry medical students, they exhibit lower self-esteem and more narcissism, and tend to compare themselves with others more often [85].

4) Analysis of the study results related to cognitive characteristics (learning)

Studies on how medical students learn cover topics such as achievement goals, being held back, learning motives, and learning styles and strategies.

Regarding achievement goals, medical students show an average level of performance-approach goals, a slight tendency toward performance-avoidance goals, and a strong level of mastery-approach goals. Students with higher performance-approach and mastery-approach goals and lower performance-avoidance goals used more diverse learning strategies and performed best academically $[47,53]$.

Males and smokers tend to have the experience of flunking and taking time off from school more [81].
According to a study in the United States, the average rate of discontinuing school is $0.55 \%$. One-fourth (25.2\%) of the students thought about discontinuing their studies and $44.1 \%$ of them considered this possibility very seriously. After flunking, students suffered from mental anxiety and expressed emotionally unstable mental conditions such as depression, paranoia, and neurotic tendencies $[81,97]$.

As for learning motives of medical students, age is the most powerful predicting variable [95]. Learning motives were higher among graduate entry medical students than medical students and among females than males. This is closely linked with learning strategies or academic achievement $[59,75]$. In studies on learning styles, most medical students are divergers and assimilators shown in the Kolb's experiential learning cycle [91]. Moreover, their most preferred learning style is kinesthetic, followed by visual, auditory, and reading and writing. They also prefer a combined learning style instead of a single one [57].

Students claimed that the passive learning strategy that focused on memorization was natural in their 6 years of education. They tend not to ask many questions in class and limit the content and number of tasks by discussing them with fellow students [101]. Medical students with greater skills in learning strategies such as time management, test management, searching for data, writing reports, giving presentations, writing, and taking notes tend to exhibit higher enthusiasm for their studies, as well as higher academic stress and satisfaction in their department [87]. Graduate entry medical students tend to use more cognitive learning and time management approaches than medical students [99].

\section{5) Analysis of the results related to social char- acteristics}

Studies on the social characteristics of medical students cover topics such as interpersonal relations, 
social support, and leadership. Medical students feel more comfortable when they work alone which is related to interpersonal relations. In other words, they feel it is difficult to solve problems if they have to discuss with others or could not share responsibilities, and feel uncomfortable with others when there are those who disagree with their opinions or criticizing their decisions [69]. Medical students show higher I-consciousness than We-consciousness compared to non-medical students. However, females express greater We-consciousness, which indicates that they place greater emphasis on personal relationships. Furthermore, students with high I-consciousness have more issues with interpersonal relations such as apathy, social avoidance, nonassertiveness and adaptability, and the desire for social acknowledgement [100].

Medical students consider their professors as superiors or targets of obedience that are challenging to deal with, and perceive the senior-junior relationship as a hierarchical one [101]. Thus, they do not consider professors or friends as someone they can seek advice from, which affected their satisfaction with school or adjustment [36]. Parents provided most of the social support for medical students, while not a single student thought of their professors as a source of social support [68,96]. Future research is needed on leadership, as there is currently none in Korea.

\section{6) Analysis of the results related to career}

Studies on the careers of medical students cover topics such as factors affecting career choices, preferred medical specialty field, motivation for entering school, and occupational values. Familiar attributes are involved in the motivation for entering medical school [22]. Students have a mixed motivation of altruistic (to help others) and intellectual reasons (interest in the study of medicine); the drive for career choices become stabilized in the students' course of study at their respective medical schools [22]. Postgraduation career choices become more specified as they move on to the later years of their education [18,33]. Higher-year students tend to make choices on their medical specialty field by considering clerkships, the learning environment, the risks of legal action, and income [55]. The difference in occupational values were different depending on their educational system, gender, and preferred medical specialty field [48].

\section{Discussion}

In this study, we examined research trends of the papers in domestics and foreign, analyze study topics and based on those we intended to establish the future research direction. Based on the results of our analysis, authors activate studies about medical student characteristics. We discussed medical school curricula and student support program development in three aspects. First, in terms of methods, most studies were crosssectional ones targeting a single medical school. In particular, Korea seriously lacked longitudinal studies in this field. Despite the remarkable recent increase in investigations on medical students [9], it is still necessary to seek changes and diversities in terms of research methods compared to overseas researches. Multiple universities need to conduct joint researches to increase the number of samples, and explore constant changes in the research subjects through longitudinal studies.

Most studies in Korea and overseas employed surveys to gather data, while data collection methods such as interviews or observations were limited to a few investigations. Quantitative research faces limitations in terms of understanding the characteristics of medical students. Recently, qualitative research has been on the rise as an alternative in order to overcome the limitations of 
quantitative research based on surveys [102]. However, the results of this paper show that qualitative research is not yet activated in the field of medical education studies. Since there are issues in generalizing the results of quantitative research from a specific research situation to other circumstances with different sociocultural contexts, it is necessary to use various methods by taking the reality of each situation into account [103]. As such, contemplating various research approaches (such as longitudinal studies and qualitative research) is a good way to minimize the limitations of generalizing study outcomes. Moreover, researchers who explore medical education must make joint efforts to establish a research environment and system to promote these techniques.

Second, topics about medical students' mental health were frequently looked into in Korea and overseas; most were about stress. This indicates that medical students face many mental obstacles in pursuing their education. Since issues of medical students' mental health can affect their studies as well as their medical behaviors (even after they become doctors). These matters are considered more important and will continue to remain a key research area in the future. However, studies in Korea did not cover drinking, smoking, drugs, or suicide at all; this may reflect cultural differences. Since these topics can be discovered in the qualitative studies such as in the process of interviewing students about students' mental health issues, it is necessary for Korean academic to pay more attention to these matters.

While there are many studies on psychological and cognitive characteristics in Korea, overseas investigations focus more on career; this shows a clear difference in research topics between the two. Studies on psychological and cognitive traits have been implemented in Korea before to develop teaching methods considering the attributes of graduate entry medical students when the system of graduate entry medical schools was implemented. In the future, it will be necessary to execute more studies that reveal the features of medical students by diversifying the subjects and comparatively interviewing medical and non-medical students alike. Subtopics of psychological or cognitive characteristics are factors with theoretically high correlation, but there is still enough research that comprehensively covers the relevance among these elements. There must be more in-depth studies on the causal relations among multiple subtopics based on pedagogical theories. Furthermore, since, after graduating medical school, careers are considered a major stress factor for Korean students [104], this matter must be covered more seriously.

Third, it is necessary to conduct more studies that develop various student support programs by considering the attributes of medical students and analyzing their effects after the program. Most papers suggested the needs to expand development of student support programs such as academic and life counseling, psychological support, career guidance, mentoring, and learning consulting $[19,20,32,33,35,36-38,46,50,63,64,68,69,87,88,90]$. The articles we reviewed lacked research that actually implemented and validated such programs. It is necessary to build up these programs to help students overcome the difficulties they face in terms of their physical and mental health, psychological characteristics, academic features, interpersonal relations, and career, which are key topics of research in our study. Furthermore, students must be able to utilize these programs actively in formal education as well as their extracurricular courses. In other words, there must be a support system based on empirical results so that we can determine suitable measures for students who cannot receive help from schools or professors, and who have issues relating to their physical health or their studies. The ultimate outcome must not just be research, but lead to genuine results so that medical students can enjoy a satisfying school life and contribute to the 
development of medical education.

We searched out for papers published in journals in Korea or overseas using leading article databases; however, there remains a possibility that some articles may have been omitted. However, our study is significant in that we attempted to conduct a scoping review of extensive literature from Korea and overseas. In addition, our study provides insights into the current state and future directions of research for scholars who want to explore the characteristics of medical students. We anticipate this will promote follow-up studies on the attributes of medical students and lead to the ongoing publication of high-quality investigations, thereby enriching basic data for student education.

\section{ORCID:}

Sung Soo Jung: https://orcid.org/0000-0001-7990-3066;

Kwi Hwa Park: https://orcid.org/0000-0002-0008-2400;

HyeRin Roh: https://orcid.org/0000-0002-3879-709X;

So Jung Yune: https://orcid.org/0000-0002-2567-0444;

Geon Ho Lee: https://orcid.org/0000-0003-0696-3804;

Kyunghee Chun: https://orcid.org/0000-0002-5351-0376

Acknowledgements: None.

Funding: This research was supported by the Korean Society of Medical Education and Korean Association of Medical Colleges.

Conflicts of interest: None.

Author contributions: SSJ: conception or design of the work, data collection, data analysis and interpretation, drafting the article; KHP: conception or design of the work, data collection, data analysis and interpretation, drafting the article, critical revision of the article, final approval of the version to be published; HRR: conception or design of the work, data interpretation; SJY: conception or design of the work, data interpretation; GHL: conception or design of the work, data inter- pretation; KHC: conception or design of the work, data interpretation.

\section{References}

1. Kwon DH. Theory and practice of educational psychology. Seoul, Korea: Hakjisa; 2009.

2. Borges NJ, Manuel RS, Elam CL, Jones BJ. Comparing millennial and generation $\mathrm{X}$ medical students at one medical school. Acad Med. 2006;81(6):571-576.

3. Borges NJ, Manuel RS, Elam CL, Jones BJ. Differences in motives between Millennial and Generation X medical students. Med Educ. 2010;44(6):570-576.

4. Twenge JM. Generational changes and their impact in the classroom: teaching Generation Me. Med Educ. 2009;43(5):398-405.

5. Kennedy GE, Judd TS, Churchward A, Gray K, Krause KL. First year students' experiences with technology: are they really digital natives? Australas J Educ Technol. 2008;24(1):108-122.

6. Kang PS, Kim DS, Lee KY, Hwang TY, Bang JB. The operating status of medical education management units in Korea. Korean J Med Educ. 2006;18(1):13-22.

7. Kim S. Current trends in medical education by analysis of Journals of Medical Education. Korean J Med Educ. 2004;16(2):109-117.

8. Lee YH, Lee YM, Kwon H. Trends analysis on research articles in the Korean Journal of Medical Education. Korean J Med Educ. 2012;24(4):287-299.

9. Yoo $\mathrm{HH}$, Shin S. Trends of research articles in the Korean Journal of Medical Education by social network analysis. Korean J Med Educ. 2015;27(4):247-254.

10. Ryue SH, Lee HB. Korean medical students' cognitive, emotional, and social characteristics. Korean J Med Educ. 2012;24(2):103-115.

11. Arksey H, O’Malley L. Scoping studies: towards a metho- 
dological framework. Int J Soc Res Methodol. 2005; 8(1):19-32.

12. Armstrong R, Hall BJ, Doyle J, Waters E. 'Scoping the scope' of a Cochrane review. J Public Health. 2011; 33(1):147-150.

13. Levac D, Colquhoun H, O’Brien KK. Scoping studies: advancing the methodology. Implement Sci. 2010;5:69.

14. Alsaggaf MA, Wali SO, Merdad RA, Merdad LA. Sleep quantity, quality, and insomnia symptoms of medical students during clinical years: relationship with stress and academic performance. Saudi Med J. 2016;37(2): 173-182.

15. Hwang IC, Park KH, Kim JJ, et al. Perceived social support as a determinant of quality of life among medical students: 6-month follow-up study. Acad Psychiatry. 2017;41(2):180-184.

16. Mahmood JI, Grotmol KS, Tesli M, Vaglum P, Tyssen R. Risk factors measured during medical school for later hazardous drinking: a 10-year, longitudinal, nationwide study (NORDOC). Alcohol Alcohol. 2016;51(1):71-76.

17. Ren GS, Min JT, Ping YS, et al. Complex and novel determinants of empathy change in medical students. Korean J Med Educ. 2016;28(1):67-78.

18. Youssef FF. Medical student stress, burnout and depression in Trinidad and Tobago. Acad Psychiatry. 2016;40(1):69-75.

19. Yu JH, Chae SJ, Chang KH. The relationship among self-efficacy, perfectionism and academic burnout in medical school students. Korean J Med Educ. 2016; 28(1):49-55.

20. AlFakhri L, Sarraj J, Kherallah S, Kuhail K, Obeidat A, Abu-Zaid A. Perceptions of pre-clerkship medical students and academic advisors about sleep deprivation and its relationship to academic performance: a crosssectional perspective from Saudi Arabia. BMC Res Notes. 2015;8:740.

21. Fang JT, Lii SC. Relationship between personality traits and choosing a medical specialty. J Formos Med Assoc. 2015;114(11):1116-1121.

22. Gąsiorowski J, Rudowicz E, Safranow K. Motivation towards medical career choice and future career plans of Polish medical students. Adv Health Sci Educ Theory Pract. 2015;20(3):709-725.

23. Hodges LE, Tak HJ, Curlin FA, Yoon JD. Whistleblowing in medical school: a national survey on peer accountability and professional misconduct in medical students. Acad Psychiatry. 2016;40(3):530-533.

24. Hojat M, Michalec B, Veloski JJ, Tykocinski ML. Can empathy, other personality attributes, and level of positive social influence in medical school identify potential leaders in medicine? Acad Med. 2015;90(4): 505-510.

25. Seo JH, Kim HJ, Kim BJ, Lee SJ, Bae HO. Educational and relational stressors associated with burnout in Korean medical students. Psychiatry Investig. 2015; 12(4):451-458.

26. Kaliyadan F, Amin TT, Qureshi H, Al Wadani F. Specialty preferences of $\mathrm{I}(\mathrm{st})$ year medical students in a Saudi medical school: factors affecting these choices and the influence of gender. Avicenna J Med. 2015;5(4): 134-139.

27. Kötter T, Pohontsch NJ, Voltmer E. Stressors and starting points for health-promoting interventions in medical school from the students' perspective: a qualitative study. Perspect Med Educ. 2015;4(3):128135.

28. Lins L, Carvalho FM, Menezes MS, Porto-Silva L, Damasceno H. Health-related quality of life of students from a private medical school in Brazil. Int J Med Educ. 2015;6:149-154.

29. Ludwig AB, Burton W, Weingarten J, Milan F, Myers DC, Kligler B. Depression and stress amongst undergraduate medical students. BMC Med Educ. 2015;15: 141. 
30. Miletic V, Lukovic JA, Ratkovic N, Aleksic D, Grgurevic A. Demographic risk factors for suicide and depression among Serbian medical school students. Soc Psychiatry Psychiatr Epidemiol. 2015;50(4):633-638.

31. Shi M, Liu L, Yang YL, Wang L. The mediating role of self-esteem in the relationship between big five personality traits and depressive symptoms among Chinese undergraduate medical students. Personal Individ Differ. 2015;83:55-59.

32. Waqas A, Khan S, Sharif W, Khalid U, Ali A. Association of academic stress with sleeping difficulties in medical students of a Pakistani medical school: a cross sectional survey. Peer J. 2015;3:e840.

33. Woolf K, Elton C, Newport M. The specialty choices of graduates from Brighton and Sussex Medical School: a longitudinal cohort study. BMC Med Educ. 2015;15:46.

34. Kim KH, Kwon KI, Jang JH, Shin M. A qualitative study on counseling experience with medical student. Korean J Couns. 2015;16(5):1-21.

35. Kim NC, Kim SH, Lhm HK, et al. Comparison of stress and life satisfaction between non-medical and medical college students. Korean J Psychosom Med. 2015;23(1): 47-56.

36. Park SY, Kwon OY, Yoon TY. Returning students' perspectives on adjusting to medical graduate school in Korea: an interview study. Korean J Med Educ. 2015; 27(1):37-44.

37. Yoo HH, Park KH. Relationships among emotional intelligence, ego-resilience, coping efficacy, and academic stress in medical students. Korean J Med Educ. 2015; 27(3):187-193.

38. Lee SH, Jeon WT. The relationship between academic self-efficacy and academic burnout in medical students. Korean J Med Educ. 2015;27(1):27-35.

39. Choi J, Son SL, Kim SH, Kim H, Hong JY, Lee MS. The prevalence of burnout and the related factors among some medical students in Korea. Korean J Med Educ.
2015;27(4):301-308.

40. Libbrecht N, Lievens F, Carette B, Côté S. Emotional intelligence predicts success in medical school. Emotion 2014;14(1):64-73.

41. Nacar M, Baykan Z, Cetinkaya F, et al. Health promoting lifestyle behaviour in medical students: a multicentre study from Turkey. Asian Pac J Cancer Prev. 2014;15(20):8969-8974.

42. O’Flynn S, Power S, Horgan M, O’Tuathaigh CM. Attitudes towards professionalism in graduate and nongraduate entrants to medical school. Educ Health (Abingdon). 2014;27(2):200-204.

43. Osama M, Islam MY, Hussain SA, et al. Suicidal ideation among medical students of Pakistan: a cross-sectional study. J Forensic Leg Med. 2014;27:65-68.

44. Soliman M. Perception of stress and coping strategies by medical students at King Saud University, Riyadh, Saudi Arabia. J Taibah Univ Med Sci. 2014;9(1):30-35.

45. Kim B, Roh H. Depressive symptoms in medical students: prevalence and related factors. Korean J Med Educ. 2014;26(1):53-58.

46. Kim SC, Choi HH. The level of fatigue severity and the quality of sleep in medical school students. Chonbuk Univ Med J. 2014;38(2):23-31

47. Kim S, Hur Y, Park JH. The correlation between achievement goals, learning strategies, and motivation in medical students. Korean J Med Educ. 2014;26(1):19-24.

48. Park KH, Yoo HH, Yim J. Medical student perception of physician values in practice by individual characteristics and preferred medical specialty field. Korean J Med Educ. 2014;26(4):309-319.

49. Park SY, Kwon I, Kwon OY, Yoon TY. A comparison of moral intuitions about professional ethics between the medical students and residents in a university hospital. Korean J Med Ethics. 2014;17(2):159-171.

50. Chun KH, Park YS, Lee YH, Kim SY. Academic burnout and selection-optimization-compensation strategy in 
medical students. Korean J Med Educ. 2014;26(4): 299-308.

51. Hur Y, Cho AR, Kim S. How well do medical students express empathy? Korean J Med Educ. 2014;26(3):217221.

52. Baldassin S, Silva N, de Toledo Ferraz Alves TC, et al. Depression in medical students: cluster symptoms and management. J Affect Disord. 2013;150(1):110-114.

53. Barkur RR, Govindan S, Kamath A. Correlation between academic achievement goal orientation and the performance of Malaysian students in an Indian medical school. Educ Health (Abingdon). 2013;26(2):98-102.

54. Choi D, Tolova V, Socha E, Samenow CP. Substance use and attitudes on professional conduct among medical students: a single-institution study. Acad Psychiatry. 2013;37(3):191-195.

55. Chung YC, Lin CY, Huang CN, Yang JH. Perceptions on gender awareness and considerations in career choices of medical students in a medical school in Taiwan. Kaohsiung J Med Sci. 2013;29(11):629-635.

56. Del-Ben CM, Machado VF, Madisson MM, Resende TL, Valério FP, Troncon LE. Relationship between academic performance and affective changes during the first year at medical school. Med Teach. 2013;35(5):404-410.

57. Kharb P, Samanta PP, Jindal M, Singh V. The learning styles and the preferred teaching-learning strategies of first year medical students. J Clin Diagn Res. 2013; 7(6):1089-1092.

58. Kim JJ, Jang EY, Park YC. Development of the scale of strategies for enhancing self-esteem among medical school students. Korean J Med Educ. 2013;25(2):89-99.

59. Kusurkar RA, Ten Cate TJ, Vos CM, Westers P, Croiset G. How motivation affects academic performance: a structural equation modelling analysis. Adv Health Sci Educ Theory Pract. 2013;18(1):57-69.

60. Miller GD, Kemmelmeier M, Dupey P. Gender differences in worry during medical school. Med Educ.
2013;47(9):932-941.

61. Nedjat S, Bore M, Majdzadeh R, et al. Comparing the cognitive, personality and moral characteristics of high school and graduate medical entrants to the Tehran University of Medical Sciences in Iran. Med Teach. 2013;35(12):el632-el637.

62. Yusoff MS. Associations of pass-fail outcomes with psychological health of first-year medical students in a malaysian medical school. Sultan Qaboos Univ Med J. 2013;13(1):107-114

63. Yusoff MS, Mat Pa MN, Esa AR, Abdul Rahim AF. Mental health of medical students before and during medical education: a prospective study. J Taibah Univ Med Sci. 2013;8(2):86-92.

64. Kim GM, Jo KH. Perception of happiness among medical students: Q methodological approach. Korean J Med Ethics. 2013;16(3):361-375.

65. Kim DW, Kim SG, Kim JH, Yang YH, Jung WY, Lee JS. Sleep and psychological problems in medical students. Sleep Med Psychophysiol. 2013;20(2):69-74.

66. Lee SJ, Park CS, Kim BJ, Lee CS, Cha BS, Kang H Circadian preference and defense in medical student Sleep Med Psychophysiol. 2013;20(2):82-87.

67. Lee SH, Lee DY. Validation of the MBI-SS Scales-based on medical school students. Asian J Educ. 2013;14(2): 165-187.

68. Lee WS, Oh YJ, Byun DY. The academic stress, depression and social support of graduate medical school students: testing the buffering effect of social support. Korean J Soc Welf Res. 2013;37:45-70.

69. Hur Y, Cho AR, Kim S. The characteristics of medical students' personality types and interpersonal needs. Korean J Med Educ. 2013;25(4):309-316.

70. Chen DC, Kirshenbaum DS, Yan J, Kirshenbaum E, Aseltine RH. Characterizing changes in student empathy throughout medical school. Med Teach. 2012;34(4): 305-311. 
71. Grayson MS, Newton DA, Thompson LF. Payback time: the associations of debt and income with medical student career choice. Med Educ. 2012;46(10):983-991.

72. Park J, Chung S, An H, et al. A structural model of stress, motivation, and academic performance in medical students. Psychiatry Investig. 2012;9(2):143-149.

73. Quince TA, Wood DF, Parker RA, Benson J. Prevalence and persistence of depression among undergraduate medical students: a longitudinal study at one UK medical school. BMJ Open. 2012;2(4):e001519.

74. Rogers ME, Creed PA, Searle J. Person and environmental factors associated with well-being in medical students. Personal Individ Differ. 2012;52(4):472-477.

75. Stegers-Jager KM, Cohen-Schotanus J, Themmen AP. Motivation, learning strategies, participation and medical school performance. Med Educ. 2012;46(7):678-688.

76. Tanaka M, Watanabe Y. Association between lifestyle and school attendance in Japanese medical students: a pilot study. Health Educ J. 2012;71(2):165-172.

77. Yap C, Rosen S, Sinclair AM, Pearce I. What undergraduate factors influence medical students when making their choice of postgraduate career? Br J Med Surg Urol. 2012;5(1):11-15.

78. Kim IH, Ko E, Kim EJ, et al. Effects of temperament and character on the specialty interests of medical students. Korean J Biol Psychiatry. 2012;19(4):199-204.

79. Yoo HH, Park JH, Kim JS, Kim HT, Kim YJ, Kim DC. Analysis of the relationship between students' seating preferences and academic achievement in medical school. Korean J Med Educ. 2012;24(2):117-125.

80. Lee KH, Ko Y, Kang KH, Lee HK, Kang J, Hur Y. Mental health and coping strategies among medical students. Korean J Med Educ. 2012;24(1):55-63.

81. Han ER, Chung EK, Oh SA, Chay KO, Woo YJ. Medical students' failure experiences and their related factors. Korean J Med Educ. 2012;24(3):233-240.

82. Crolla E, O’Sullivan H, Bogg J. Gender and medical leadership: student perceptions and implications for developing future leaders in primary and secondary care: a pilot study. J Prim Care Community Health. 2011; 2(4):225-228.

83. Gurpinar E, Bati H, Tetik C. Learning styles of medical students change in relation to time. Adv Physiol Educ. $2011 ; 35(3): 307-311$.

84. Karlıkaya C, Ozdemir L. Did unprogrammed tobacco control efforts over seven years decrease smoking prevalence in the medical school? Tuberk Toraks. 2011 59(1):18-26.

85. Kim JH, Jang EY, Kim D, Choi JH, Park YC. Mental health of medical school students and the effects of their strategy for enhancing self-esteem. Korean J Med Educ. $2011 ; 23(4): 295-304$

86. Taber BJ, Hartung PJ, Borges NJ. Personality and values as predictors of medical specialty choice. J Vocat Behav. $2011 ; 78(2): 202-209$.

87. Park M. The relationships among learning behaviors, major satisfaction, and study skills of first-year medical students. Korean J Med Educ. 2011;23(2):83-93.

88. Yune SJ, Park KH, Chung WJ, Lee SY. The effects of attribution tendencies, academic stress, and coping efficacy on academic adjustment of medical students. Korean J Med Educ. 2011;23(3):167-174.

89. Hur Y, Lee KH. Analysis of medical students' enneagram personality types, stress, and developmental level. Korean J Med Educ. 201 1;23(3):175-184.

90. Dyrbye LN, Thomas MR, Power DV, et al. Burnout and serious thoughts of dropping out of medical school: a multi-institutional study. Acad Med. 2010;85(1):94-102.

91. Gurpinar E, Alimoglu MK, Mamakli S, Aktekin M. Can learning style predict student satisfaction with different instruction methods and academic achievement in medical education? Adv Physiol Educ. 2010;34(4): 192-196.

92. Habeeb KA. Prevalence of stressors among female 
medical students Taibah University. J Taibah Univ Med

Sci. 2010;5(2):110-119.

93. Henning M, Krageloh C, Hawken S, Zhao Y, Doherty I. Quality of life and motivation to learn: a study of medical students. Issues Educ Res. 2010;20(3):244-256.

94. Honney K, Buszewicz M, Coppola W, Griffin M. Comparison of levels of depression in medical and nonmedical students. Clin Teach. 2010;7(3):180-184.

95. Kusurkar R, Kruitwagen C, ten Cate O, Croiset G. Effects of age, gender and educational background on strength of motivation for medical school. Adv Health Sci Educ Theory Pract. 2010;15(3):303-313.

96. Mustafa MB, Nasir R, Yusooff F. Parental support, personality, self-efficacy and depression among medical students. Procedia Soc Behav Sci. 2010;7:419-424.

97. Kyeon YG, Cho SM, Hwang HG, Lee KU. The effects of perfectionism on academic achievement in medical students. Korean J Med Educ. 2010;22(3):205-214.

98. Kim HJ, Cha SM, Kim JL, Wang SK, Chee IS. Dissatisfied body part and personality characteristics in a Korean medical student sample. J Korean Soc Biol Ther
Psychiatry. 2010;16(2):148-155.

99. Shin HI, Jeon WT, Yang EB. Relationship between learning strategies and academic achievement in medical college and graduate medical school students. Korean J Med Educ. 2010;22(3):197-204.

100. Yang EB, Jeon W, Ryue SH. The relationship between the level of I-conscousness We-consciousness and interpersonal problems of Korean medical students. Korean J Med Educ. 2010;22(2):141-148.

101. Chun KH, Park WK, Lee SS, Park YS, Kang E. A study on the educational climate, self-directed learning and creative thinking in medical school. Int J Creat Probl Solving. 2010;6(1):179-200.

102. Na J. A comparative analysis of validity issues in qualitative research. J Educ Eval. 2006;19(1):265-283.

103. Sung TJ. Introduction to educational research. Seoul, Korea: Hakjisa; 2016.

104. Kim MJ, Park KH, Yoo HH, Park IeB, Yim J. Development and validation of the medical student stress scale in Korea. Korean J Med Educ. 2014;26(3): 197-208. 